\title{
Improving the efficiency of an electric drive with a cylindrical linear alternating current electronic engine
}

\author{
Dmitrii Andreevich Chirkov, Aleksandr Dmitrievich Korotayev, Evgenii Aleksandrovich Chabanov \\ The Department of Electrical Engineering and Electrical Mechanics, The Electrical Engineering Faculty, Perm National Research \\ Polytechnic University, Perm, the Russian Federation
}

\begin{tabular}{l} 
Article Info \\
\hline Article history: \\
Received Oct 4, 2021 \\
Revised Jan 17, 2022 \\
Accepted Jan 24, 2022 \\
\hline
\end{tabular}

Keywords:

Electric machine simulation

Electromechanics

Energy efficiency

Linear motors

Oil field operation

Plane finish machines

\begin{abstract}
Currently, linear motors find increasingly wide application in various industrial sectors. These motors feature a range of advantages including the absence of compound mechanical power transmissions between a motor and an actuator, simple design, and performance reliability. These advantages determine application of linear motors in electric drive systems of a range of industrial mechanisms including liquid metal and melt transfer units, various transport systems, and metal working and grinding machines. As an illustration, the article addresses submersible cylindrical linear alternating current electronic engines used for rodless oil extraction. Practice shows that the overall efficiency of such units is extremely low. This article is dedicated to the determination of performance and power/angle characteristics of such linear motors, their main energy indicators $\cos \varphi$ and efficiency at various supply voltage frequencies. It is shown that $\cos \varphi$ at all supply voltage frequencies remains very high, while the efficiency is extremely low. The main way to increase the engine efficiency is to increase the frequency of its supply voltage as much as possible. It is proposed to extend the results obtained to other possible industrial applications of linear electric drives.
\end{abstract}

This is an open access article under the CC BY-SA license.

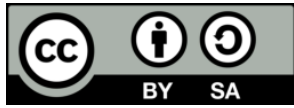

\section{Corresponding Author:}

Evgenii Aleksandrovich Chabanov

The Department of Electrical Engineering and Electrical Mechanics

Perm National Research Polytechnic University

Room 351, Main Academic Building, 29, Komsomolsky prospekt, Perm, 614990, Russia

Email: ceapb@mail.ru

\section{INTRODUCTION}

Over the years, the production sector has been dependent on various belt and screw drives, mechanical devices and mechanisms used to perform the translational and reciprocating movement of the working body. Such devices, despite all the simplicity of their design, have a number of disadvantages: low bandwidth, a small number of operating cycles, the setting is not flexible enough or completely absent, there is no programming option. However, at present, the opposite is required from units intended for the organization of reciprocating motion. Direct-drive linear motor technology provides high-quality linear positioning solutions. Linear motors use the principle of interaction of a linearly moving magnetic field of a stationary inductor and a massive secondary element moving along a guide. In this case, there is no need to use any additional mechanical transducers, and, therefore, the linear electric motor is capable of providing linear movement [1].

A linear electric motor is a device in which a secondary element linearly moves along an open magnetic circuit of arbitrary length. The inductor winding creates a linearly running magnetic field inside the magnetic circuit. In industry, the most widespread are cylindrical electric motors, in which the rotor (secondary element) and the stator (primary element) are rolled up in the form of hollow cylinders. The 
inductor and secondary element of the linear motor are deployed in strips, i.e., have a flat shape. The running magnetic field of the motor is created by alternately switching the coils of the inductor winding. A linear electric alternating current (AC) motor consists of an armature with a winding wound around its surface, which is a commutator (a guiding element), and an open magnetic core with field windings (a moving member). These windings are located so that the force vectors of one pole are in the same direction. The simple regulation of the moving member's speed is a distinctive feature of the linear motor. AC motors can be synchronous and asynchronous [2]. The armature in an asynchronous linear motor has the form of a bar, normally rectangular in section and without winding. The armature is mounted along the travel path of the unit's moving member fitted with a magnetic core with straight-line multi-phase windings fed by an AC source. The interaction of the magnetic field of the moving member's magnetic core and the armature field produces forces that cause the moving member to move faster relative to the stationary armature. The process occurs until equalisation of the speed of the moving member and the running magnetic field.

Linear motors are used in a range of actuators. The applications include overhead crane trolley travel mechanisms, smoke ventilation automated control systems, drill rig operating units feed mechanisms, water supply to effective downhole plunger pumps, electric transportation systems, as well as permanent-magnet mechatronic units in machining equipment for operating unit movement [3]. The simple design with no rubbing elements ensures direct conversion of energy flow within the magnetic field into mechanical energy, thus resulting in the machine's high efficiency and reliability [4].

Let us take a closer look at the application of linear motors in oil industry in Russia. As of today, two main oil production methods prevail in Russia: using sucker rod pump units and electric submersible pump units. Sucker rod pump units feature a number of advantages including relatively high efficiency at low to medium flow rates, and a displacement pump suitable for application in heavy-oil and sandy wells and with high gas-oil ratio. That being said, sucker rod pump units have a significant drawback: the production depth is limited to 2,000 meters due to the risk of rod string parting. The key advantages of electric submersible pump units include low metal consumption, possibility of production at depths greater than 2,000 meters and application in directional wells. However, electric submersible pump units have a significant drawback: their application is limited to high-rate wells only since their efficiency when producing less than $80 \mathrm{~m}^{3} /$ day goes below 35\% [5]. Therefore, such units shall only be used at high-rate wells. The impracticability of using sucker rod pump units for deep wells, and electric submersible pump units for medium- and low-rate wells has built the need to develop fundamentally new designs of oil production units. Currently, there is only one practical solution to the problem of producing oil from medium- and low-rate wells with a depth of 2,000 $\mathrm{m}$ and greater, consisting in the use of a submersible rodless pump unit using the cylindrical linear AC electronic engine [6]. A rodless submersible pumping unit for oil production began to be developed in the 1920s [7]. Figure 1 shows the arrangement of an submersible rodless pump unit at the well.

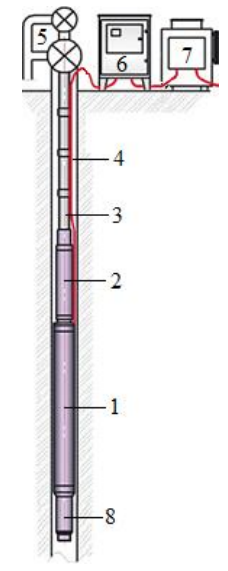

Figure 1. Submersible rodless pump unit's arrangement at a well

\section{METHOD}

Figure 1 shows the cylindrical linear AC electronic engines 1 actuates plunger of pump 2, which lifts fluid in oilwell tubing 3 . The motor is powered through armored three-core cable 4 passing through wellhead equipment 5; and is connected to control system 6 . The station is connected to the three-phase mains through transformer 7 . The submersible rodless pump unit is fitted with telemetry system 8 . 
Earlier developments of submersible rodless pump units driven by linear induction motors didn't progress since no sufficient traction forces could be obtained from wells [8]. Considerable progress in the production of rare-earth permanent magnets [9] fueled the development of submersible rodless pump units driven by a linear cylindrical motor (e.g., cylindrical linear AC electronic engine), which nowadays allows to obtain the required traction capacities.

The production units' energy consumption is a high-priority issue in oil production. Pilot field trials conducted by Rosneft Oil Company have shown a significant advantage in energy efficiency with the use of submersible rodless pump units at wells with medium and low flow rates over electric submersible pump units [10]. However, as practice shows, the overall efficiency of these units is very low, not exceeding $30 \%$ [11]. The article contains the results of studies of the cylindrical linear AC electronic engine, which were carried out under a state order. Figure 2 shows a longitudinal section of the cylindrical linear AC electronic engine, on the secondary element of which permanent magnets are placed.

According to the picture, the engine consists of [12]:

- Cylindrical body (hollow cylinder)

- Inductor, fixed in the housing and recruited from cups with coils of a three-phase winding stacked in them, forming a traveling magnetic field along the motor axis.

- Secondary element that carries out linear movement inside the inductor and is made up of permanent magnets and non-magnetic inserts.

The cylindrical linear AC electronic engine consists of separate micro modules that are 0.1 meters long, depending on the traction effort required, the number of micro modules and the length of the actual cylindrical linear AC electronic engine on Figure 3 can be altered [13]. The studied cylindrical linear AC electronic engine's module was 1 meter long. On the inductor there are prongs and grooves in which there are cylindrical coils of the stator. Pole pitch $\tau=30 \mathrm{~mm}$, slot pitch $t_{z}=10 \mathrm{~mm}$. The coils connect sequentially over the length of the inductor and form a three-phase winding that is powered by a frequency converter. The winding of the cylindrical inductor creates a running magnetic field, the speed and direction of which are changed via of a frequency converter [14]. The secondary element has a diameter of $D_{p}=53 \mathrm{~mm}$. The gap $\delta$ between the stationary inductor and the secondary element moving inside it is $1.5 \mathrm{~mm}$.

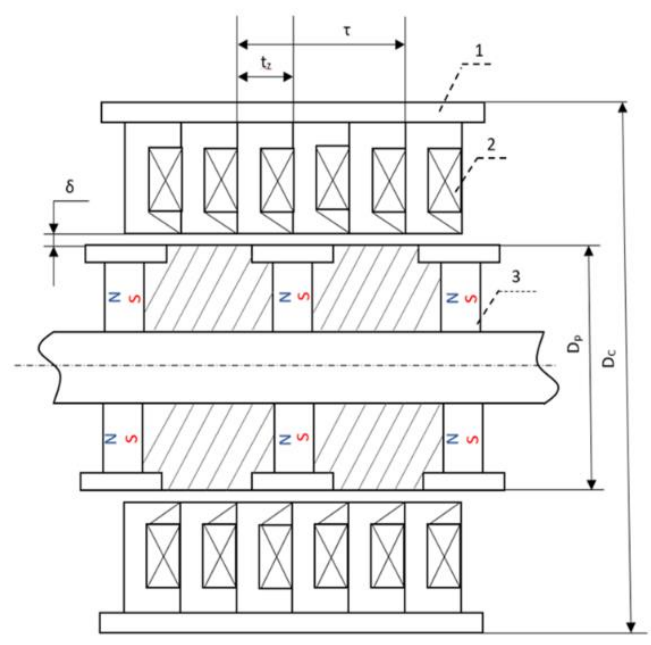

Figure 2. Cut away side view of the cylindrical linear AC electronic engine

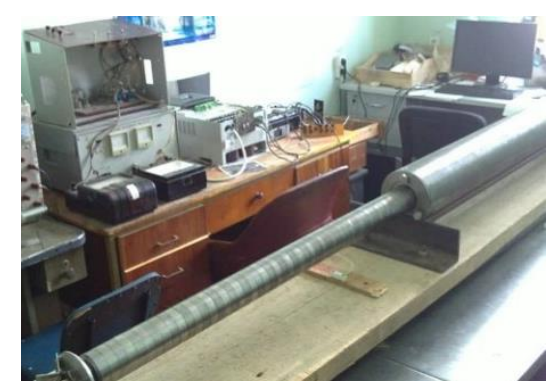

Figure 3. Module of the cylindrical linear AC electronic engine with control system 
The Department of Electrical Engineering and Electrical Mechanics of the Perm National Research Polytechnic University designed and manufactured the cylindrical linear AC electronic engine module, as well as the control system for it [15]. The nominal force of the control system of the engine if $4 \mathrm{kN}$ with a length of one meter and phase current 30 A [16]. To study the dependencies of traction force and efficiency of the cylindrical linear AC electronic engine with permanent magnets, a mathematical model based on the electrical and magnetic circuit concept was developed according to [17]. For a magnetic circuit design, an equivalent circuit of the cylindrical linear AC electronic engine was built with reference to [18]. To refine the design of this equivalent circuit, the following updates have been made; i) Leakage reluctance along the crown of tooth have been added; ii) Magnetomotive force sources of motor windings have been added.

The components of the magnetic resistance (longitudinal and transverse) are calculated according to separate equivalent circuits. Magnetic resistances of circuit sections with radial magnetic flux were determined in integral form with allowance for their increasing cylindrical cross-section. Therefore, the magnetic circuit shall be defined numerically using any applicable software. The motor's mathematical model was developed using MathCAD. To determine the circuit resistances, the system of Kirchhoff equations is solved in relation to magnetic fluxes. Since the resistances of circuit sections are non-linear functions of the magnetic flux passing through them, an analytical solution of the equations is not realistic. Therefore, the solution is generated using iterative method. The number of iterations equals 20 , which gives a maximum error of $2 \mu \mathrm{Wb}$. The calculation of force using this method can be compared in accuracy with finite element method [19].

Magnetic resistances of the circuit section where magnetic flux is perpendicular and parallel to motor axis are determined by formulas,

$$
R_{r}=\int_{r_{1}}^{r_{2}} \frac{H(\Phi / S(r))}{\Phi} d r, R_{z}=\frac{l \cdot H(\Phi / S)}{\Phi}
$$

where $r_{1}$ and $r_{2}$ are radial coordinates of the beginning and end of the considered section $r_{1}-r_{2}$ of the magnetic circuit (for $R_{r}$ ); $H=H(B)=H\left(\frac{\Phi}{S}\right)$ is the magnetic intensity on the section $r_{1}-r_{2}$ (for $R_{z}$ ) or the magnetic intensity on the elementary radial increment $d r$ of the section $r_{1}-r_{2}$ (for $R_{r}$ ); $S$ is the crosssectional area of the section $r_{1}-r_{2}\left(S=S(r)\right.$ for $\left.R_{r}\right) ; \Phi$ is the magnetic flux penetrating the section $r_{1}-r_{2}$; $l$ is the length of the section $r_{1}-r_{2}$.

The longitudinal and transverse magnetic resistances are determined separately as functions of the motor current $R_{d}(I), R_{q}(I)$. The no-load magnetic flux $\Phi_{0}$ required for further calculations is determined as the magnetic flux in air gap, generated by permanent magnets, but subject to magnetic circuit saturation obtained in the iterative calculations. The longitudinal and transverse magnetic resistances are determined separately as functions of the motor current components of the motor's inductive resistance $X_{d}$ и $X_{q}$ are determined from the obtained magnetic resistances. The no-load electromotive force of one phase of the inductor winding is determined, as follows:

$$
E_{0}(f, I)=f \cdot e_{0}(I)=f \cdot 4,44 \cdot w \cdot \Phi_{0}(I) \cdot k_{\text {об }}
$$

where $w$ is the number of turns, $k_{\text {об }}$ is the winding factor.

The calculation of the cylindrical linear AC electronic engine's magnetic circuit and determination of longitudinal and transverse inductances of the motor have allowed to develop a mathematical model of the motor. The longitudinal and transverse components of stator currents and total current are calculated in accordance with the vector diagram shown in Figure 4, by setting the magnitude and nature of the supply voltage and the load angle $\theta$ :

$$
I_{d}=\frac{X_{q} \cdot\left(U \cdot \cos (\theta)-E_{0}\right)-r_{s} \cdot U \cdot \sin (\theta)}{X_{d} \cdot X_{q}+r_{s}^{2}}, I_{q}=\frac{r_{s} \cdot\left(U \cdot \cos (\theta)-E_{0}\right)+X_{d} \cdot U \cdot \sin (\theta)}{X_{d} \cdot X_{q}+r_{s}^{2}}, I=\sqrt{I_{d}^{2}+I_{q}^{2}}
$$

where $r_{s}$ is the equivalent active resistance of the three motor phases.

With known values of the longitudinal and transverse components of the stator current, the maximum main and reactive forces are defined mathematically by the expressions obtained from [17],

$$
F_{\varepsilon m}=\frac{3 \cdot U \cdot E_{0}}{2 \tau \cdot f\left(X_{d} X_{q}+r_{s}^{2}\right)^{2}} \cdot \sqrt{\left(X_{d} X_{q}^{2}+2 \cdot r_{s}^{2} X_{d}-r_{s}^{2} X_{q}\right)^{2}+r_{s}^{2}\left(2 X_{q}{ }^{2}-X_{d} X_{q}+r_{s}^{2}\right)^{2}}
$$




$$
F_{d q m}=\frac{3 \cdot U^{2} \cdot\left(X_{d}-X_{q}\right)}{4 \tau \cdot f\left(X_{d} X_{q}+r_{s}^{2}\right)^{2}} \cdot \sqrt{\left(X_{d}^{2}+r_{s}^{2}\right) \cdot\left(X_{q}^{2}+r_{s}^{2}\right)}
$$

main and reactive braking forces,

$$
F_{\varepsilon T}=-\frac{3 \cdot E_{0}^{2} \cdot r_{s}}{2 \tau \cdot f\left(X_{d} X_{q}+r_{s}^{2}\right)^{2}} \cdot\left(X_{q}^{2}+r_{s}^{2}\right), F_{d q T}=-\frac{3 \cdot U^{2} \cdot r_{s}}{2 \tau \cdot f\left(X_{d} X_{q}+r_{s}^{2}\right)^{2}} \cdot\left(X_{d}-X_{q}\right)^{2}
$$

main and reactive force displacement angles.

$$
\alpha_{\varepsilon}=\operatorname{arctg}\left(\frac{r_{s}\left(2 X_{q}^{2}-X_{d} X_{q}+r_{s}^{2}\right)}{X_{d} X_{q}^{2}+2 \cdot r_{s}^{2} X_{d}-r_{s}^{2} X_{q}}\right), \alpha_{d q}=\operatorname{arctg}\left(\frac{r_{s}\left(X_{d}+X_{q}\right)}{X_{d} X_{q}-r_{s}^{2}}\right) \text {. }
$$

The result is the synchronous force value.

$$
F_{C}=F_{\varepsilon m} \cdot \sin \left(\theta+\alpha_{\varepsilon}\right)+F_{\varepsilon T}+F_{d q m} \cdot \sin 2\left(\theta+\alpha_{d q}\right)+F_{d q T} .
$$

The useful and consumed power equals the following,

$$
P_{2}=F \cdot v, P_{s}=P_{2}+I^{2} \cdot r_{s},
$$

where $v=2 \cdot \tau \cdot f$ is the linear speed of the secondary element, the pole pitch value $\tau=30 \mathrm{~mm}$, where $I^{2} \cdot r_{S}$ is the copper losses of all the three motor phases. The efficiency and power factor,

$$
\eta=\frac{P_{2}}{P_{S}}, \cos (\phi)=\frac{P_{S}}{S}
$$

where gross power $S=U \cdot I$

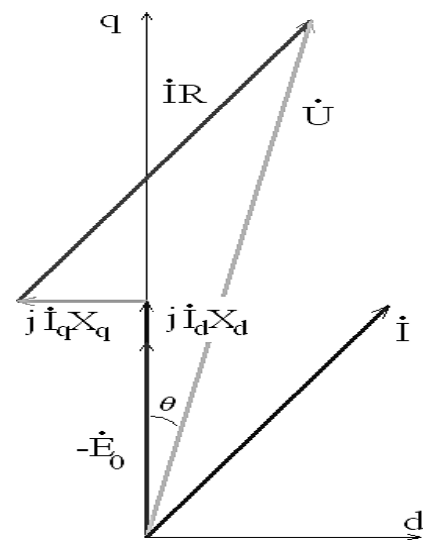

Figure 4. Cylindrical linear AC electronic engine's vector diagram

\section{RESULTS}

Figures 5, 6 and 7 show the simulation results, namely, the dependencies of power consumption $P_{1}$, traction force $F$ and current consumption $I$ on power released at the secondary element of the cylindrical linear AC electronic engine $P_{2}$ at different supply voltage frequencies $f_{s v}$ of $1 \mathrm{~Hz}, 7 \mathrm{~Hz}$ and $10 \mathrm{~Hz}$. These dependencies have been calculated for the cylindrical linear AC electronic engine's prototype at a rated phase current consumption of $30 \mathrm{~A}$, because the nominal operating mode of the engine is of particular interest and is the maximum possible, in which the motor is able to perform the function assigned to it for a long period of time.

When $f_{s v}=1 \mathrm{~Hz}$, both resistances $\mathrm{Z}$ and $\mathrm{R}$ are almost equal, so $\cos \varphi \approx 1$ (see Figure 5). Factor $\cos \varphi$ falls with increasing $f_{s v}\left(\cos \varphi=0.93\right.$ at $f_{s v}=7 \mathrm{~Hz} ; \cos \varphi=0.90$ at $\left.f_{s v}=10 \mathrm{~Hz}\right)$. This is a good energy indicator. 


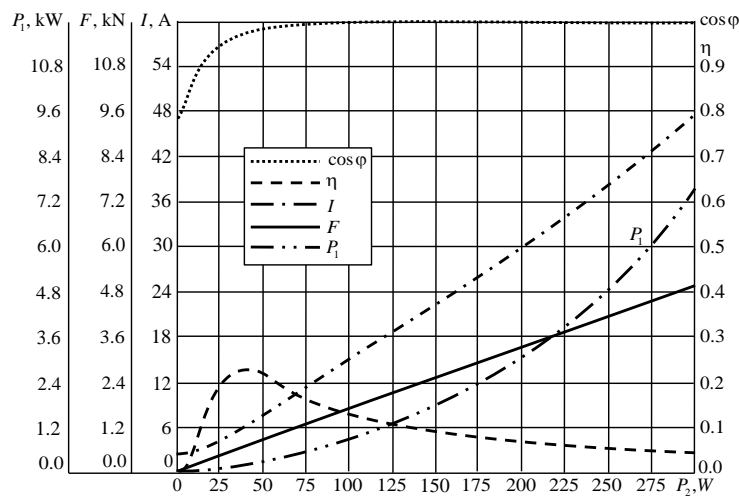

Figure 5. Cylindrical linear AC electronic engine's performance characteristics at $f_{s v}=1 \mathrm{~Hz}$

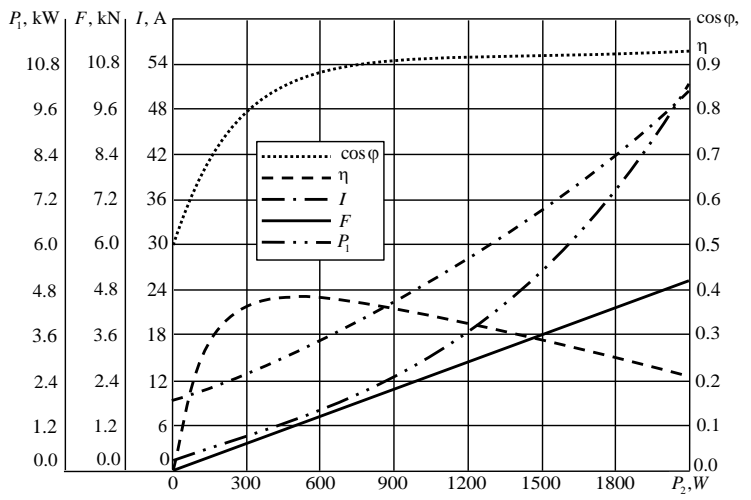

Figure 6. Cylindrical linear AC electronic engine's performance characteristics at $f_{s v}=7 \mathrm{~Hz}$

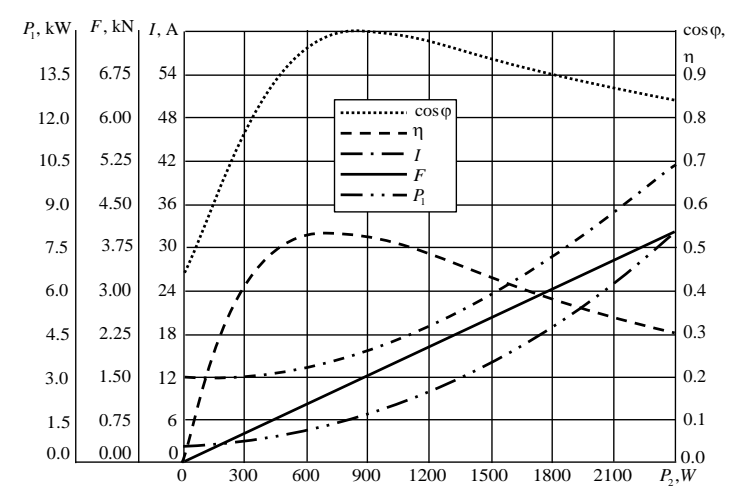

Figure 7. Cylindrical linear AC electronic engine's performance characteristics at $f_{s v}=10 \mathrm{~Hz}$

The load has a significant effect on the efficiency of the motor as shown in Figures 5, 6, and 7. The traction force $F$ and the useful power $P_{2}$ increase in proportion to the consumed current $I$, and the heat losses in the stator windings have a square-law dependence on the current, therefore, the efficiency changes from zero to the maximum value with increasing load, and then significantly decreases. Thus, according to Figure 5, at a frequency $f=1 \mathrm{~Hz}$ and at rated current the efficiency is 7\%, according to Figure 6-at $f=7$ $\mathrm{Hz}$ it is $32 \%$ and according to Figure $7-$ at $f=10 \mathrm{~Hz}$ it is $38 \%$. The efficiency of the motor decreases with increasing load, because the current consumed from the source increases, which means that the heat losses in the winding increase significantly due to the high active resistance $R$. The operation of the motor according to Figures 5, 6, and 7 at higher speeds of movement of the secondary element is preferable. The efficiency of the engine in such operating modes increases with a growth of the frequency $f_{s v}$ and the speed $v$, which leads to an improvement in energy performance.

The traction force varies from 3200 to $3300 \mathrm{~N}$ at all frequencies of the supply voltage and the rated current of the primary winding. Therefore, the traction force remains practically constant. This will significantly reduce the cycle time. In order to provide the required number of double strokes $0.5-8$ per minute, it is necessary to enter a time pause between cycles [20], or to increase the return time.

Subsequent studies carried out at LLC «Oil Avtomatika» showed:

- Comparative analysis of simulation results and data obtained experimentally on a prototype showed their high degree of convergence [19].

- In the presence of acceleration and deceleration accelerations, in addition to the appearance of restrictions on the maximum frequency, there also appears an extremum in the energy efficiency of the working stroke with the same tractive effort.

- The most energy efficient is the continuous operation without pauses with the fastest working stroke and the slowest reverse.

The motor stator magnetic core should be made laminated using electrical steel. This will reduce losses in steel, which increase significantly with increasing frequency $f_{s v}$. The traction force created by the motor is inversely proportional to the losses in steel, therefore, with an increase in the frequency $f_{s v}$ from 1 $\mathrm{Hz}$ to $10 \mathrm{~Hz}$, the force decreases by $12.64 \%$ (see Table 1), and the no-load current, which creates a working 
magnetic field in the magnetic circuit of the inductor, begins to grow. This is due to the change in the structural composition of the consumed current [21]: the reactive component increases; the active component decreases. Further to the performance curves, the power/angle curves of the cylindrical linear AC electronic engine were plotted, as well. The power/angle characteristics for frequencies 1,7 and $10 \mathrm{~Hz}$ are shown in Figure 8 .

Table 1. Cylindrical linear AC electronic engine's performance characteristics analysis for various frequencies $f_{s v}$

\begin{tabular}{cccc}
\hline Frequency, $\mathrm{Hz}$ & Traction force at rated current, $\mathrm{N}$ & Efficiency at rated current, $\%$ & No-load current, A \\
\hline 1 & 3480 & $7 \%$ & 2 \\
7 & 3120 & $32 \%$ & 9,5 \\
10 & 3040 & $38 \%$ & 12 \\
\hline
\end{tabular}

The frequency $f_{s v}$ has a significant effect on the power/angle curves of the motor (Figure 8). The motor's impedance grows disproportionately to the frequency $f_{s v}$ due to the large active component in its composition. This causes the no-load current to increase greatly when the frequency is increased from 1 to $10 \mathrm{~Hz}$.

The no-load electromotive force grows in proportion to the supply voltage frequency while the motor's impedance does not, resulting in an increase in no-load current and a drop in traction force of the motor. However, a further increase in frequency should result in a slowdown in the traction force drop, as the impedance becomes predominantly inductive and the efficiency increases further. However, this will increase the eddy-current losses in the motor, which will require an imbricated coil.

The low supply voltage frequencies $(1$ to $10 \mathrm{~Hz}$ ) needed to obtain the required speeds of the secondary element allow the inductor magnetic system to be manufactured from standard structural steel, which considerably simplifies manufacture and reduces the cost of the cylindrical linear AC electronic engine. Additional research carried out in the Maxwell program allowed the creation and calculation of a new rationalized design of the motor with an open groove, teeth of laminated electrical steel and magnets (Table 2).

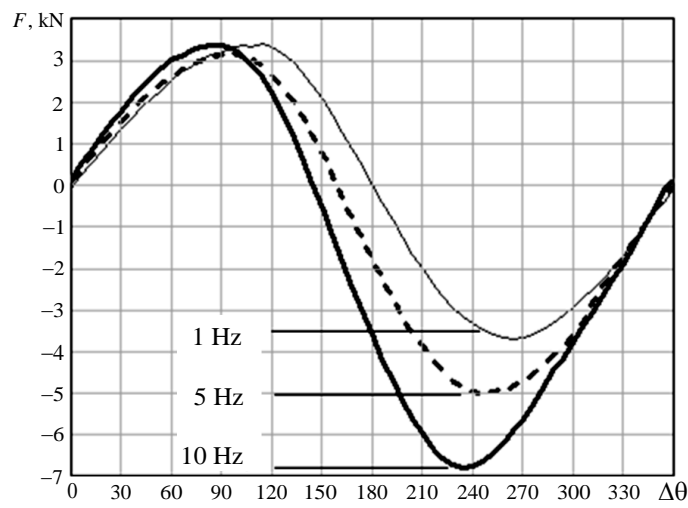

Figure 8. Motor's power/angle characteristics at $f_{s v}=1, f_{s v}=7, f_{s v}=10 \mathrm{~Hz}$

Table 2. Parameters of the original and rationalized designs of the cylindrical linear AC electronic engines

\begin{tabular}{|c|c|c|c|c|c|c|c|c|}
\hline $\begin{array}{l}\text { Construction of } \\
\text { cylindrical linear AC } \\
\text { electronic engine }\end{array}$ & Magnet brand & $\begin{array}{r}\mathrm{M} \\
\text { chara } \\
B_{r}, \mathrm{~T}\end{array}$ & $\begin{array}{l}\text { Magnet } \\
\text { acteristics } \\
H_{c}, \mathrm{kA} / \mathrm{m}\end{array}$ & $\begin{array}{c}F_{B} \\
\mathrm{~N}\end{array}$ & $\begin{array}{c}F_{H} \\
\mathrm{~N}\end{array}$ & $\begin{array}{c}F_{B M}, \\
\mathrm{~N}\end{array}$ & $\begin{array}{c}F_{H M} \\
\quad \mathrm{~N}\end{array}$ & $\begin{array}{c}\text { Efficiency for } f=7 \\
\Gamma ц, \%\end{array}$ \\
\hline Rationalized design & Tula plant of permanent magnets & 1.47 & 1138 & 2285 & 2715 & 9140 & 10860 & 51 \\
\hline Rationalized design & OJSC «Magnetron», c. Vladimir & 1.26 & 900 & 2053 & 2337 & 8212 & 9348 & 48 \\
\hline Rationalized design & $\begin{array}{l}\text { «POZ-Progress», c. Yekaterinburg, } \\
\text { Pyshma }\end{array}$ & 1 & 680 & 1685 & 1886 & 6740 & 7544 & 42 \\
\hline Original design & $\begin{array}{l}\text { «POZ-Progress», c. Yekaterinburg, } \\
\text { Pyshma }\end{array}$ & 1 & 680 & 1100 & 960 & 4400 & 3840 & 33 \\
\hline
\end{tabular}

The efficiency improvement problem is not so acute in low-power electric drives built on the basis of the cylindrical linear AC electronic engine, while its design and reciprocation features allow using linear motors in other industries. Thus, there is a recent tendency in mechanical engineering to ramp up the 
production of flat parts with high accuracy; special plane finish machines are being used for this purpose. The cylindrical linear AC electronic engine can be used to drive the reciprocating motion of these machines. Its application as a drive is the most promising as the machine's operating conditions can be adjusted within a wide range. Two perpendicular linear drives of the machine allow to arbitrary vary the linear axes travel and the frequency of such movement. This feature allows to implement any movement, including Lissajous patterns, without having to change the machine's mechanical system. Thus, any motion trajectory can be implemented with automation-set laws only by adjusting the control signals of the drive controlled by a microcontroller [22].

The basic operating principle of the actuator's axes is a reciprocating movement of the working plane, which is connected by means of a rod with electric motors, such as cylindrical linear AC electronic engine. The main advantage of the cylindrical linear AC electronic engine in this apparatus is a holding torque due to permanent magnets on the secondary element and a possibility of implementing an arbitrary control law. It also features operating unit rapid movement.

The linear motors will be powered by three-phase cables from two frequency converters mounted next to a flat operating unit and controlled by a microcontroller, in conjunction with a PC. Earlier, a control flow chart for one electric drive of the cylindrical linear AC electronic engine in reciprocating motion mode was developed to control the actuator. The initial parameters for system operation are set depending on a geometry and time of workpiece processing. The output values for the frequency converter are calculated based on the program flow chart [23].

It must be taken into account that perpendicular drives, based on cylindrical linear AC electronic engine, shall be synchronized over a control law set by the microcontroller to obtain the required trajectory of the operating unit. Using a PC allows to change the machine control laws arbitrarily by adjusting the program within the microcontroller. Such a complex control system consisting of a microcontroller and a PC is essential to implement to the full extent the real-time drive motion as they must be synchronised in time to thus obtain the required trajectory accuracy. Therewith, the stroke length and double stroke frequency vary within specified limits depending on input parameters [16].

The control system algorithm allows to correctly control the cylindrical linear AC electronic engine. The movement is carried out in both directions: forward and backward. At the same time, the stroke length and double stroke frequency shall vary within specified limits depending on input parameters, as well as to control the cylindrical linear AC electronic engine's temperature [1], [24], [25].

Both cylindrical linear AC electronic engines together with the control and synchronisation system are basic elements of a surface grinding machine with the possible two degrees of movement $(\mathrm{X}, \mathrm{Y})$ of the lapping disc in Figure 9. The technical result is a simplification of the mechanical power transmission system through the use of two linear reciprocating electric motors respectively powered by two frequency-controlled inverters with adjustable lapping plate vibration amplitude, and a reduction of the machine's mass and size parameters.

The surface finish device contains lapping plate 1, lifter 2, rotor 3 of linear motor 4 of reciprocating motion along the $X$ axis, slot 5 of the machine bed, housing 4 of the linear motor, sensors Dp 6 and Ds 7, a control system CS of inverter 8 feeding the stator of linear motor 4; in the Y axis in the perpendicular direction the second linear motor connected through second lifter $2 \mathrm{y}$ to rotor $3 \mathrm{y}$ of the second linear motor $4 \mathrm{y}$ of reciprocating motion along the $\mathrm{Y}$ axis, slot 5y of the machine bed, housing $4 \mathrm{y}$ of the second linear motor, sensors Dp 6y and Ds 7y, two inverters 8, two electric motors 4, pantograph 9; travel amplitudes dL1 and dL2 of lapping plate 1 and housing 4 of the linear motor are measured by sensors Dp and Ds, respectively, their signals being processed under the control system program of inverter 8 feeding the stator of linear motor 4 .

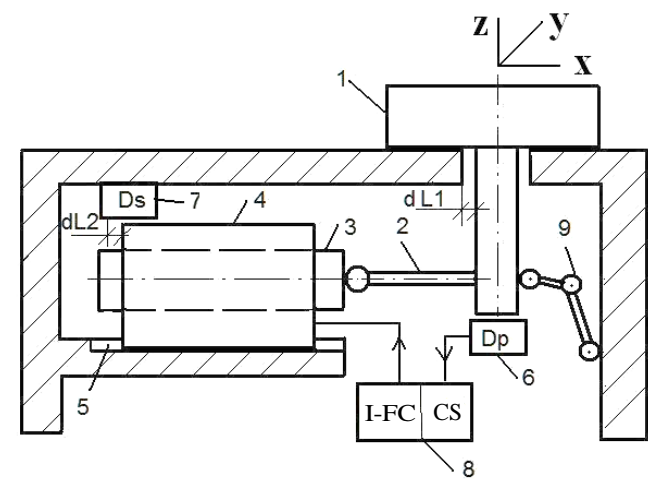

Figure 9. Surface-grinding machine configuration: control system (CS); inverter-frequency converter (I-FC) 


\section{CONCLUSION}

It is necessary to increase the proportion of inductive resistance in the engine to increase the efficiency of the cylindrical linear AC electronic engine as part of the submersible rodless pump unit. This can be achieved either by increasing the supply voltage frequency and optimizing the motor algorithm, or by optimizing its design. The implementation of these recommendations will entail an increase in the cost of the submersible rodless pump unit's installation. Thus, the motor operation algorithm optimization will demand increase in a power stroke frequency, which in turn will demand increased supply voltage, this in its turn demanding more powerful and expensive control systems and power oil transformers. Further, the motor design optimization will demand increase in amount of permanent magnets and use of advanced materials and will complicate the cylindrical linear AC electronic engine's manufacture technology. The cost per pole pair will mount up dramatically. However, according to preliminary estimates, introduction of these measures will allow to raise the unit's efficiency. Then the total cost of a submersible rodless pump unit's package will grow by approximately $20-40 \%$.

Increasing the cylindrical linear AC electronic engine's efficiency will entail a significant reduction in energy consumption. By estimation, the cost difference between the basic and optimized submersible rodless pump unit's packages will be repaid in less than a year of operation, even in regions with low electricity prices. It should also be noted that improving the efficiency of oil production units is feasible, and while it involves essential costs, it will pay off multiple times in electricity costs over the submersible unit's life cycle. The problem of increasing the efficiency of the cylindrical linear AC electronic engine is not so acute in low-power electric drives used in other areas of industry, because the main requirements in this case are high accuracy, repeatability and resolution of the positioning of the working body.

\section{ACKNOWLEDGEMENTS}

The research was carried out with financial support from the Ministry of Science and Higher Education of the Russian Federation under state assignment FSNM-2020-0028.

\section{REFERENCES}

[1] Z. Q. Zhu and D. Howe, "Influence of design parameters on cogging torque in permanent magnet machines," IEEE Transactions on Energy Conversion, vol. 15, no. 4, pp. 407-412, Dec. 2000, doi: 10.1109/60.900501.

[2] V. Dmitrievskii, V. Prakht, and V. Kazakbaev, "Synchronous reluctance generator with ferrite magnets for wind turbine," IOP Conf. Series: Journal of Physics: Conf., Nov. 2018. doi:10.1088/1742-6596/1102/1/012041.

[3] Z. Fengwu, "Electric submersible Pump lifting process optimization," Proceedings of 2013 2nd International Conference on Measurement, Information and Control, 2013, pp. 1328-1331, doi: 10.1109/MIC.2013.6758204.

[4] S. V.-Zadeh and A. R. Ghasemi, "Design Optimization of Permanent magnet Synchronous Motors for High Torque Capability and Low Magnet Volume," Electric Power Systems Research, vol.74, no. 2, pp. 307- 313, Mar. 2005, doi: 10.1016/j.epsr.2004.11.008.

[5] A. Yashin and M. Khakimyanov, "Characteristics Analysis of Linear Submersible Electric Motors for Oil Production," 2020 Russian Workshop on Power Engineering and Automation of Metallurgy Industry: Research \& Practice (PEAMI), 2020, pp. 1519, doi: 10.1109/PEAMI49900.2020.9234346.

[6] V. A. Volkov and S. R. Razmanova, "Technological modernization of the oil and gas industry: the current state and prospects of development," St. Petersburg State Polytechnical University Journal Economics, vol. 251, no. 5, pp. 30-40. doi: 10.5862/JE.251.3

[7] V. V. Anikin, V. Z. Kovalev, R. N. Khamitov, and V. O. Bessonov, "Study of asynchronous electric motors in the electrical complex of oil production," Young Russia: advanced technologies into industry, 2019, doi:10.25206/2310-4597-2019-1-24-28

[8] P. Iliushin, R. Rakhimzianov, D. Solov'ev, and I. Kolychev, "Analysis of well intervention aimed at oil production enhancement in the Perm krai's fields," PNRPU Bulletin. Geology. Oil and gas and mining, no. 15, pp. 81-89, 2015. doi: 10.15593/22249923/2015.15.9

[9] L. H. Lewis and F. J.-Villacorta, "Perspectives on permanent magnetic materials for energy conversion and power generation." Metallurgical and Materials Transactions A, vol. 44, no. 1, pp. 2-20, 2013, doi: 10.1007/s11661-012-1278-2.

[10] G. Takacs, "Electrical Submersible Pumps Manual. Design, Operations, and Maintenance," Elsevier Inc, January 2009.

[11] D. Lei, X. Huang, H. Zhang, M. Yao, R. Chen, and J. Liu, "Optimization and application of reciprocating direct-drive electric submersible plunger pump lifting system in the Xinjiang oilfield," The Open Chemical Engineering Journal, vol. 13, no. 1, 2019, DOI: $10.2174 / 1874123101913010068$.

[12] G. R. Mingaleeva, I. V. Dmitrienko, A. I. Zdorov, A. N. Nikolaev, E. V. Shamsutdinov, and O. V. Afanaseva, “ Tension force of cylindrical linear van motor with permanent magnets between stator and secondary element," Scientific Review Technical Science. [Online]. Available: https://science-engineering.ru/ru/article/view?id=422

[13] Y. Liu, X. Liu, and C. Sun, "Comparative Study of Electromagnetic Performance of Multi-Tooth Switching Flux Permanent Magnet Memory Machine," 2018 IEEE Student Conference on Electric Machines and Systems, 2018, pp. 1-5, doi: 10.1109/SCEMS.2018.8624830.

[14] J. W. Finch and D. Giaouris, "Controlled AC Electrical Drives," IEEE Transactions on Industrial Electronics, vol. 55, no. 2, pp. 481-491, Feb. 2008, doi: 10.1109/TIE.2007.911209.

[15] D. A. Chirkov and E. O. Timashev, "Efficiency of a submersible plunger pump linear motor," E3S Web of Conferences, vol. 140, 2019, doi: 10.1051/e3sconf/201914002012.

[16] A. T. Klyuchnikov, A. D. Korotaev, and S. V. Shutemov, "Modeling of a cylindrical linear AC electronic motor," Russian 
Electrical Engineering, vol. 84, no. 11, pp. 606-609, doi: 10.3103/S1068371213110059.

[17] N. V. Shulakov and S. V. Shutemov, "A method for calculating the electromagnetic processes in a cylindrical linear electronic motor," Russian Electrical Engineering, vol. 85, pp. 663-667, 2014, doi: 10.3103/S1068371214110121.

[18] I. Smolyanov, F. Sarapulov, and F. Tarasov, "Calculation of linear induction motor features by detailed equivalent circuit method taking into account non-linear electromagnetic and thermal properties," Computers \& Mathematics with Applications, vol. 78, no. 9, Jun. 2019, doi: 10.1016/j.camwa.2019.05.015

[19] E. O. Timashev, D. A. Chirkov, and A. D. Korotaev, "Operating characteristics of a cylindrical linear induction motor," Russian Electrical Engineering, vol. 89, pp. 643-647, 2018, doi:10.3103/S1068371218110135.

[20] A. N. Drozdov and E. S. Skvortsova, "Application of Linear Valve Submersible Electric Motors in Oil Production Units for Marginal Wells," IOP Conference Series Earth and Environmental Science, vol. 666, no. 6, p.062012, Mar. 2021. doi: $10.1088 / 1755-1315 / 666 / 6 / 062012$

[21] Z. Bubnicki, "Modern Control Theory," Publisher: Springer-Verlag Berlin, Heideberg, Germany ISBN: 3-540-23951-0, January 2005 .

[22] Q. Zhu, L. Liu, W. Zhang, and S. Li, "Control of Complex Nonlinear Dynamic Rational Systems," Hindawi, vol. 2018, pp. 1-12, Jun. 2018, doi: 10.1155/2018/8953035.

[23] A. S. Vostrikov and V. D. Yurkevich, "Design of control systems by means of localisation method," Preprints of 12-th IFAC World Congress, 1993.

[24] G. X.-Cun, L. Bin, L. Z.-Yuan, and Z. Ran, "Research on Performance High-speed Multi-stage Cylinder Linear Induction Motor," Energy Procedia, vol. 16, pp. 1904-1912, 2012, doi: 10.1016/j.egypro.2012.01.291.

[25] Y. K. Kwon et al., "Performance test of a 1 MW class HTS synchronous motor for industrial application," Physica C: Superconductivity, vol. 468, no. 15-20, pp. 2081-2086, 2008, doi: 10.1016/j.physc.2008.05.249.

\section{BIOGRAPHIES OF AUTHORS}

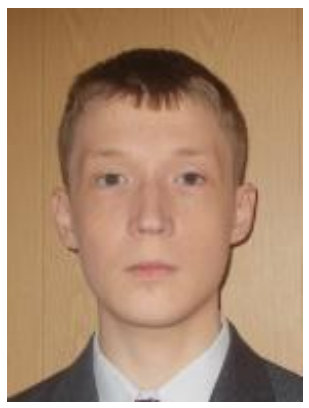

Dmitrii Andreevich Chirkov (D) SC P candidate of Sciences in Technology (Ph.D. in Technology), Lead Engineer of the Center for Additive Technologies, Perm National Research Polytechnic University, Perm city, the Russian Federation. He can be contacted at email: chirkov146@gmail.com.

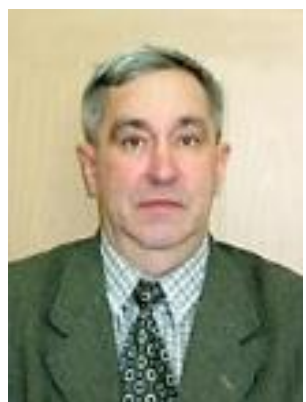

Aleksandr Dmitrievich Korotaev (D) If SC P candidate of Sciences in Technology (Ph.D. in Technology), Associate Professor, Associate Professor of the department of Electrical Engineering and Electrical Mechanics, Electrical Engineering Faculty, Perm National Research Polytechnic University, Perm city, the Russian Federation. He can be contacted at email: alexanderkorotaev16@gmail.com.

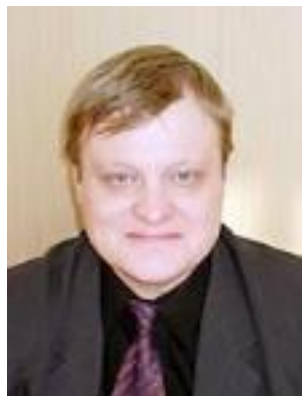

Evgenii Aleksandrovich Chabanov (D) \& sc P candidate of Sciences in Technology (Ph.D. in Technology), Associate Professor, Associate Professor of the department of Electrical Engineering and Electrical Mechanics, Electrical Engineering Faculty, Perm National Research Polytechnic University, Perm city, the Russian Federation. He can be contacted at email: ceapb@mail.ru. 